\title{
Erratum to: Clomiphene Citrate co-treatment with low dose urinary FSH versus urinary FSH for clomiphene resistant PCOS: randomized controlled trial
}

\author{
Mohamad E. Ghanem • Laila A. Elboghdady • Mohamad Hassan • Adel S. Helal • \\ Ahmed Gibreel • Maha Houssen • Mohamed E. Shaker • Ibrahiem Bahlol • Yaser Mesbah
}

Published online: 1 March 2014

(C) Springer Science+Business Media New York 2014

\section{Erratum to: J Assist Reprod Genet (2013) 30:1477-1485 DOI 10.1007/s10815-013-0090-2}

The original publication of this article contained mistakes. Below is the letter to the editor for the details.

\section{Dear Editor,}

We appreciate very much the remarks shown by Dr. Athanasios Papathanasiou, regarding our paper. We would like to thank him for his interest in our work.

We admit that some editing errors had been passed unnoticed, throughout the process of submission, reviewing and production, within Table 2 . The correct numbers and corresponding calculations are provided in the below table.

The online version of the original article can be found at http://dx.doi.org/ 10.1007/s10815-013-0090-2.

M. E. Ghanem • L. A. Elboghdady · M. Hassan · A. S. Helal •

I. Bahlol

Mansoura Integrated Fertility Center, Mansoura, Egypt

M. E. Ghanem • L. A. Elboghdady • M. Hassan · A. S. Helal •

A. Gibreel $(\varangle) \cdot$ I. Bahlol $\cdot$ Y. Mesbah

Department of Obestetrics \& Gynecology, Mansoura Faculty of

Medicine, Mansoura, Egypt

e-mail: ahmedfathgi@yahoo.com

\section{Houssen}

Department of Biochemistry, Faculty of Pharmacy, Damanhur University, Damanhur, Egypt

\section{E. Shaker}

Department of Pharmacology \& Toxicology, Faculty of Pharmacy, Mansoura University, Mansoura, Egypt

\begin{tabular}{|c|c|c|c|c|c|}
\hline & $\begin{array}{l}\text { All } \\
\text { cycles }\end{array}$ & Group I (\%) & Group II (\%) & $\mathrm{RR}(95 \% \mathrm{CI})$ & $\mathrm{P}$ \\
\hline $\begin{array}{l}\text { Ovulation Rate / } \\
\text { per woman } \\
\text { randomized b }\end{array}$ & $\begin{array}{r}96 / 174 \\
(55.1)\end{array}$ & $\begin{array}{l}63 / 87 \\
\quad(72.4)\end{array}$ & $33 / 87(37.9)$ & $1.9(1.4-2.5)$ & $<0.001$ \\
\hline $\begin{array}{r}\text { Ovulation Rate / } \\
\text { per Protocol b }\end{array}$ & $\begin{array}{r}96 / 159 \\
(60.3)\end{array}$ & $\begin{array}{l}63 / 82 \\
\quad(76.8)\end{array}$ & $33 / 77(42.8)$ & $1.8(1.3-2.4)$ & $<0.001 \mathrm{~d}$ \\
\hline
\end{tabular}

$\mathrm{b}=\mathrm{n}(\%)$

$\mathrm{d}=$ Fisher's exact test

It is clear from the table that the provided values resulted in almost the same statistical differences and thereby same conclusion. Dr. Papathanasiou has admitted that the statistical significance observed in our study was not changed after making the amendments. Meanwhile, he expressed his concern that the effect size statistics may have changed. Our research question was whether clomiphene citrate plus gonadotropins was as equal as gonadotropins alone or not, in terms of ovulation rate. The questions about the effect size and the number needed to treat may be important points when making inference and recommendations for the general population. In our study we acknowledged the need for larger trial or a metaanalysis of small randomized trials. Either of these, may be the optimum platform to calculate statistical measures as effect size and number needed to treat.

As regards predictors of ovulation, we attempted to underline the relative importance of features of CC-resistant PCOS as predictors of treatment outcome. Although multivariate analysis was the better statistical tool for this purpose, yet, and as suggested by our statistician, the ROC curve has been used in similar situations [1,2].

Dr. Papathanasiou has mentioned contradiction between the confidence interval $(0.51-0.77)$ and the $p$ value $(0.05)$, the reported $\mathrm{P}$ value of ( 0.05$)$ resulted from summing up of 
the computer output from 0.049 to 0.05 based on an advice from our medical statistician.

Finally, we thank Dr Papathanasiou for his valuable comments that, up to our opinion, would not undermine the validity of this randomized trial.

Yours faithfully,

Ahmed Gibreel, M.D., MRCOG

\section{References}

1. Imani B, Eijkemans J, te Velde R, Habbema D, Fauser C. Predictors of Patients Remaining Anovulatory during Clomiphene Citrate Induction of Ovulation in ormogonadotropic Oligoamenorrheic Infertility. J Clin Endocrinol Metab. 1998;83:2361-5.

2. Wely V, Bayram N, van der Veen F, Bossuyt M. Predicting ongoing pregnancy following ovulation induction with recombinant FSH in women with polycystic ovary syndrome. Human Reprod. 2005;20:1827-32. 